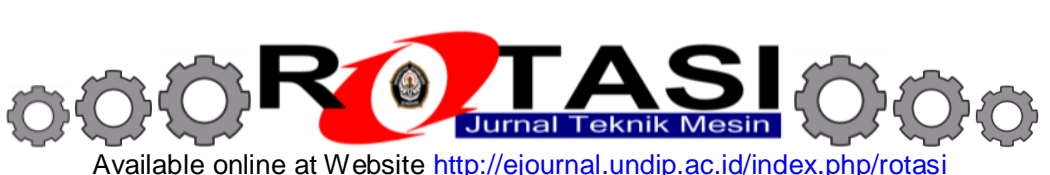

Available online at Website http://ejournal.undip.ac.id/index.php/rotasi

\title{
PERANCANGAN MESIN REMAS (SQUEEZE MACHINE) UNTUK TERAPI AUTISME
}

\author{
*Awan Raswan, Sumar Hadi Suryo, Jamari, Ismoyo Haryanto \\ Program Studi Magister Teknik Mesin, Fakultas Teknik, Universitas Diponegoro \\ Jl. Prof. Sudharto, SH., Tembalang-Semarang 50275, Telp. +62247460059 \\ *E-mail: mega_ras132@yahoo.com
}

\begin{abstract}
The last two decades, in the world of autism increased dramatically. In 1990 obtained 4 from 10000 births (1: 2500). In 2000 to 2008 be 1: 88, increased nearly 30 fold. Deep pressure therapy is a method of providing the pressure and the amount of time on the outside of the body most deeply and evenly. Deep pressure generated by stress relieving device, such as squeeze machine. Squeeze machine can give the effect of calmness to the people hypersensitive to sensory stimulation, such as autism.

In Indonesia, squeeze machine is still rare because the price is quite expensive. As needed, it should be designed at an affordable price without compromising quality. Phase of the design process, namely: (1) project definition, project planning, and preparation of technical specifications of the product, (2) the design concept of the product, (3) designing embodiment product, and (4) preparation of documents for the manufacture of products.

Squeeze machine model design concept originated from the use of the prone position, deep pressure of a $V$ shaped wall. Squeeze machine design usage position supine position, deep pressure of the three arms, namely: (1) hand and body, (2) the hip and thigh, and (3) the lower leg. For ages under 8 - 9 years, deep pressure 30 - 40 psi within 15 - 45 minutes. At the end of the design process gained some documents as the basis for the manufacture of prototypes, namely: (1) layout drawing, (2) arrangement drawing (assembly), (3) detail element drawing, and (4) the bill of materials.
\end{abstract}

Keywords: autism, deep pressure, design, squeeze machine.

\section{PENDAHULUAN}

Anak dengan kebutuhan khusus (special needs) yang mempunyai gangguan perkembangan di Indonesia, yang perlu diberikan pelayanan diantaranya adalah anak dengan hendaya autisme (impairment autistic children). Secara umum anak autisme mengalami gangguan berbicara disamping mengalami gangguan kemampuan intelektual dan fungsi saraf serta kelainan perilaku yang ganjil dan mempunyai kehidupan sosial yang aneh serta terlihat seperti orang yang selalu sakit, tidak suka bergaul, dan sangat terisolasi dari lingkungan hidupnya. Anak autisme yang mempunyai gangguan perkembangan seperti tersebut di atas, memerlukan suatu metode dan perangkat terapi yang sifatnya khusus (berkaitan dengan pembentukan fisik, emosi, sosialisasi, dan daya nalar) [2].

\subsection{Perkembangan Autisme}

Dalam dua dekade terakhir ini, autisme di dunia meningkat drastis. Setiap dekade terjadi peningkatan sekitar 10 kali lipat. Tahun 1990 hanya didapat 4 dari 10000 kelahiran (1:2500) [9]. Tahun 2001 meningkat menjadi 1:100, peningkatan sebesar 25 kali lipat. Tahun 2008 menjadi 1:88, peningkatan mencapai hampir 30 kali lipat [1].

\subsection{Perilaku Autisme}

Perilaku autisme dapat digolongkan dalam 2 jenis, yaitu: (1) perilaku eksesif (berlebihan), dan (2) perilaku defisit (berkekurangan). Perilaku eksesif seperti hiperaktif dan tantrum (mengamuk) berupa menjerit, menyepak, menggigit, mencakar, memukul, dan kadang menyakiti diri sendiri (self abuse). Disamping itu, seringkali memperlihatkan perilaku stimulus diri seperti berputar-putar, mengepak-ngepak tangan seperti sayap, berjalan berjinjit dan lain sebagainya. Sedangkan perilaku defisit ditandai dengan gangguan bicara, perilaku kurang sesuai, defisit sensoris sehingga dikira tuli, bermain tidak benar dan emosi yang tidak tepat, misalnya tertawa, menangis tanpa sebab atau diam dalam keadaan melamun [7]. Contoh sebagian perilaku anak autisme, seperti pada Gambar 1.

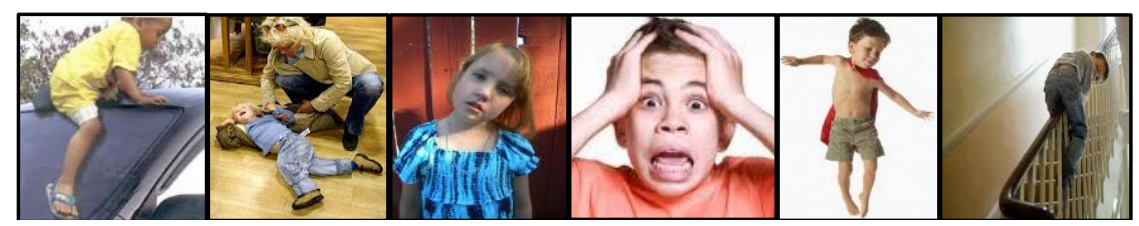

Gambar 1. Contoh perilaku anak autisme [5]. 


\subsection{Terapi Autisme}

Metode terapi autisme yang sedang berkembang saat ini diantaranya adalah metode deep pressure. Metode deep pressure merupakan pemberian tekanan tertentu dan dalam waktu tertentu secara mendalam pada sebagian besar tubuh bagian luar secara merata. Stimulasi deep pressure diterapkan pada sepanjang kedua sisi tubuh, dengan tekanan lateral mendorong ke dalam seluruh bagian tubuh. Ruang bebentuk V menekan tubuh secara penuh dari kepala sampai kaki, tanpa menghasilkan titik-titik tekanan tertentu, sehingga pengguna benar-benar dapat merasakan relaksasi. Pada penahan bagian kepala dan leher ditutupi dengan bulu palsu yang lembut. Ketika menutup, hal ini meningkatkan perasaan tenang seperti berada dalam pelukan dari deep pressure [4].

Pengalaman Grandin pada usia 3 tahun, memiliki gejala autisme standar seperti intoleransi untuk disentuh, ketidakmampuan untuk berbicara, amukan, dan perilaku stereotypic. Grandin sangat kaku dan sensitif terhadap sentuhan dan suara, dan menarik diri ketika orang menyentuhnya. Deep pressure membantu dalam mengatasi masalah oversensitivity terhadap sentuhan, dan dapat menghilangkan kegugupan. Seperti halnya pada anak-anak dengan gangguan autisme dan attention deficit hyperactivity disorder (ADHD) [4].

\subsection{Perangkat Terapi Autisme}

Perangkat terapi autisme untuk menghilangkan kecemasan dan ketegangan (stress relieving device) diciptakan pertama kali oleh Temple Grandin pada tahun 1982 dinamakan squeeze machine. Sketsa squeeze machine ciptaan Temple Grandin seperti pada Gambar 2.

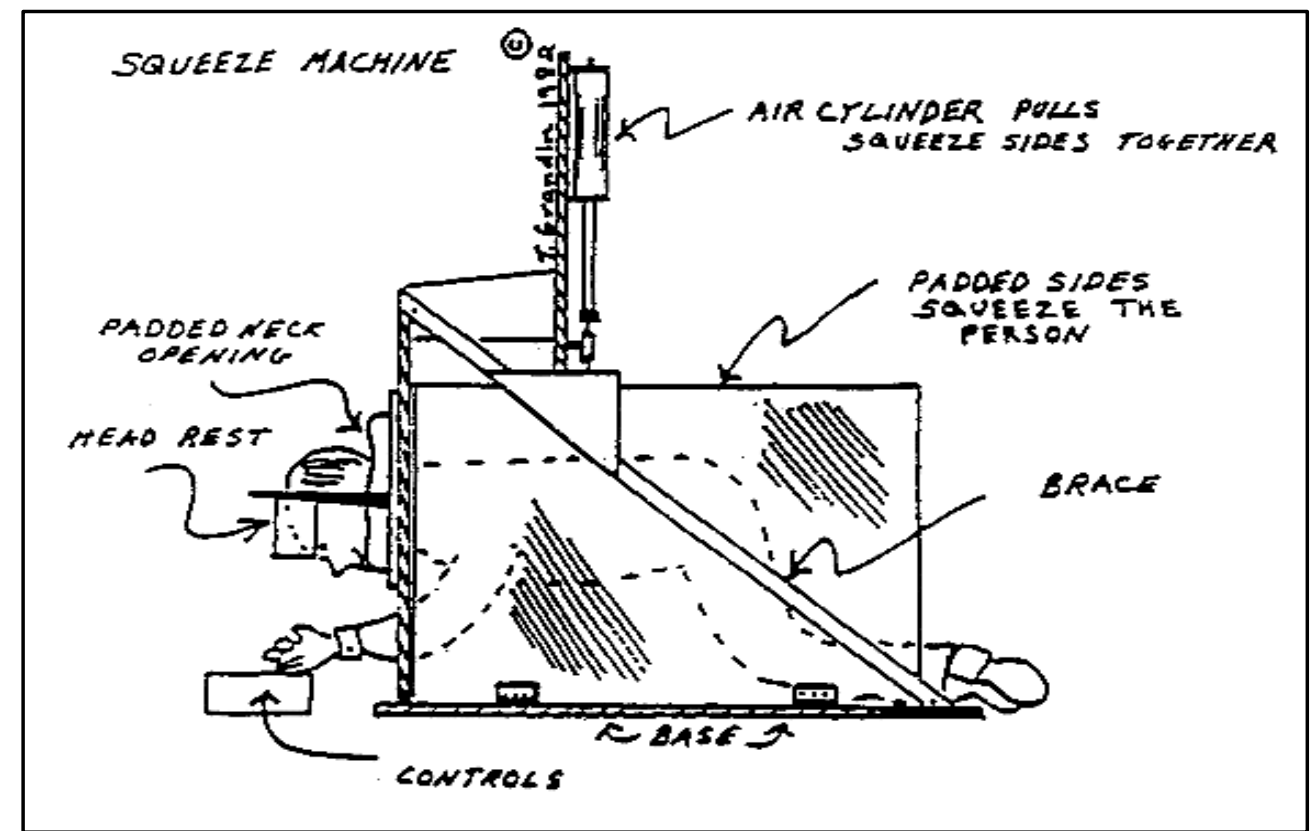

Gambar 2. Sketsa rancangan squeeze machine [3].

Gambar 3a menunjukkan squeeze machine ciptaan Temple Grandin dan produksi Therafin Corporation, seperti dapat dilihat pada Gambar 3b.

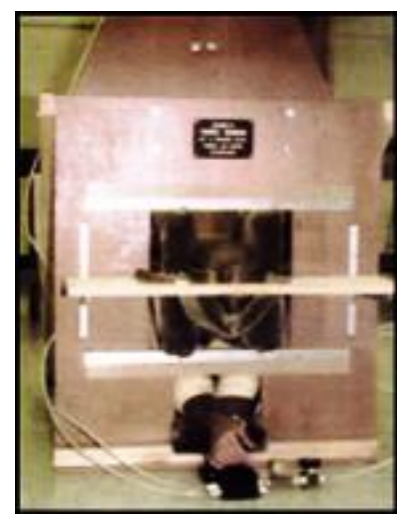

Gambar 3a. Squeeze machine Ciptaan Temple Grandin [10].

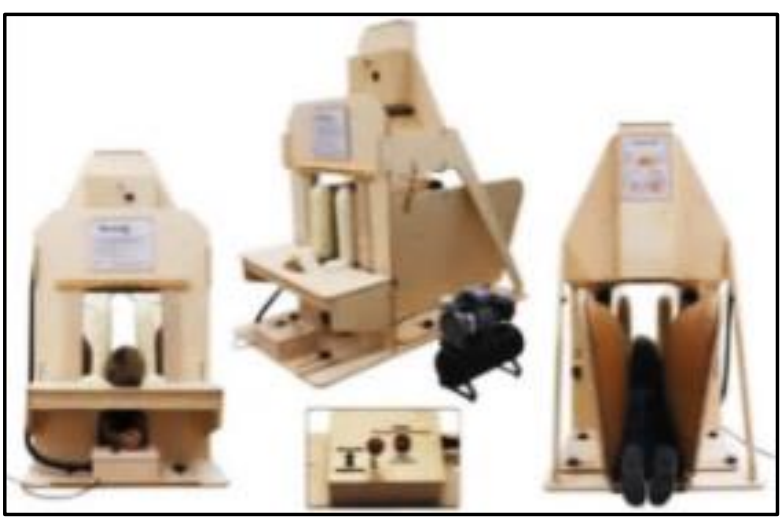

Gambar 3b. Squeeze machine produksi Therafin Corporation [6]. 
Squeeze machine yang dikembangkan oleh Temple Grandin terdiri dari dua sisi papan berbentuk V yang berengsel di bagian bawahnya. Pengguna melangkah ke dalam mesin dan berbaring di dalam ruang berbentuk V. Permukaan bagian dalam squeeze machine dilapisi dengan busa tebal yang empuk. Pengguna mengontrol penuh atas besarnya tekanan yang diterapkan melalui sebuah tuas yang dioperasikan melalui katup pneumatik. Tuas yang terhubung ke silinder udara, menarik sisi papan secara bersama-sama. Sehingga pengguna memungkinkan untuk mengatur sendiri besarnya tekanan yang diterapkan. Untuk orang dewasa, tekanan udara pada silinder berdiameter $5 \mathrm{~cm}$ ditetapkan sebesar 60 psi, yang memungkinkan hingga berat badan antara $43-95 \mathrm{~kg}$. Untuk anak di bawah usia $8-9$ tahun, tekanan diatur pada $30-40$ psi dengan waktu 15 - 45 menit [3].

Dalam satu dekade terakhir ini, beberapa terapi okupasi dan psikologi (occupational therapists and psychologists) di Amerika telah menggunakan squeeze machine untuk sensory integrative theraphy pada anak autisme dan hiperaktif. Lorna King, director of center for neurodevelopmental studies di Phoenix (Arizona), menyatakan bahwa saat ini ada enam squeeze machine sedang digunakan untuk terapi integratif sensorik, dan efeknya sangat baik dan menguntungkan pada anak autisme dan attention deficit hyperactivity disorder (ADHD) atau ketidakmampuan belajar. Margaret Creedon di Michael Reese Hospital Chicago juga menyatakan bahwa anak-anak dengan gangguan perkembangan pervasif (PDD) dan anak-anak dengan gangguan Tourette telah menggunakan squeeze machine dan dapat menenangkan mereka, selain itu mengklaim dapat membantu menghambat mengamuk dan mengurangi stereotipik [4].

\section{METODOLOGI PENELITIAN}

Perancangan produk adalah sebuah proses yang berawal dari ditemukannya kebutuhan terhadap suatu produk sampai diselesaikannya gambar-gambar dan dokumen hasil rancangan yang dipakai sebagai dasar untuk pembuatan produk. Ada beberapa fase perancangan yang harus dilalui dalam proses perancangan produk, yaitu: (1) fase definisi proyek, perencanaan proyek dan penyusunan spesifikasi teknis produk, (2) fase perancangan konsep produk, (3) fase perancangan pemberian bentuk (embodiment) produk, dan (4) fase penyusunan dokumen untuk pembuatan produk. Untuk lebih jelasnya, dapat dilihat pada diagram alir proses perancangan produk seperti pada Gambar 4 [8].

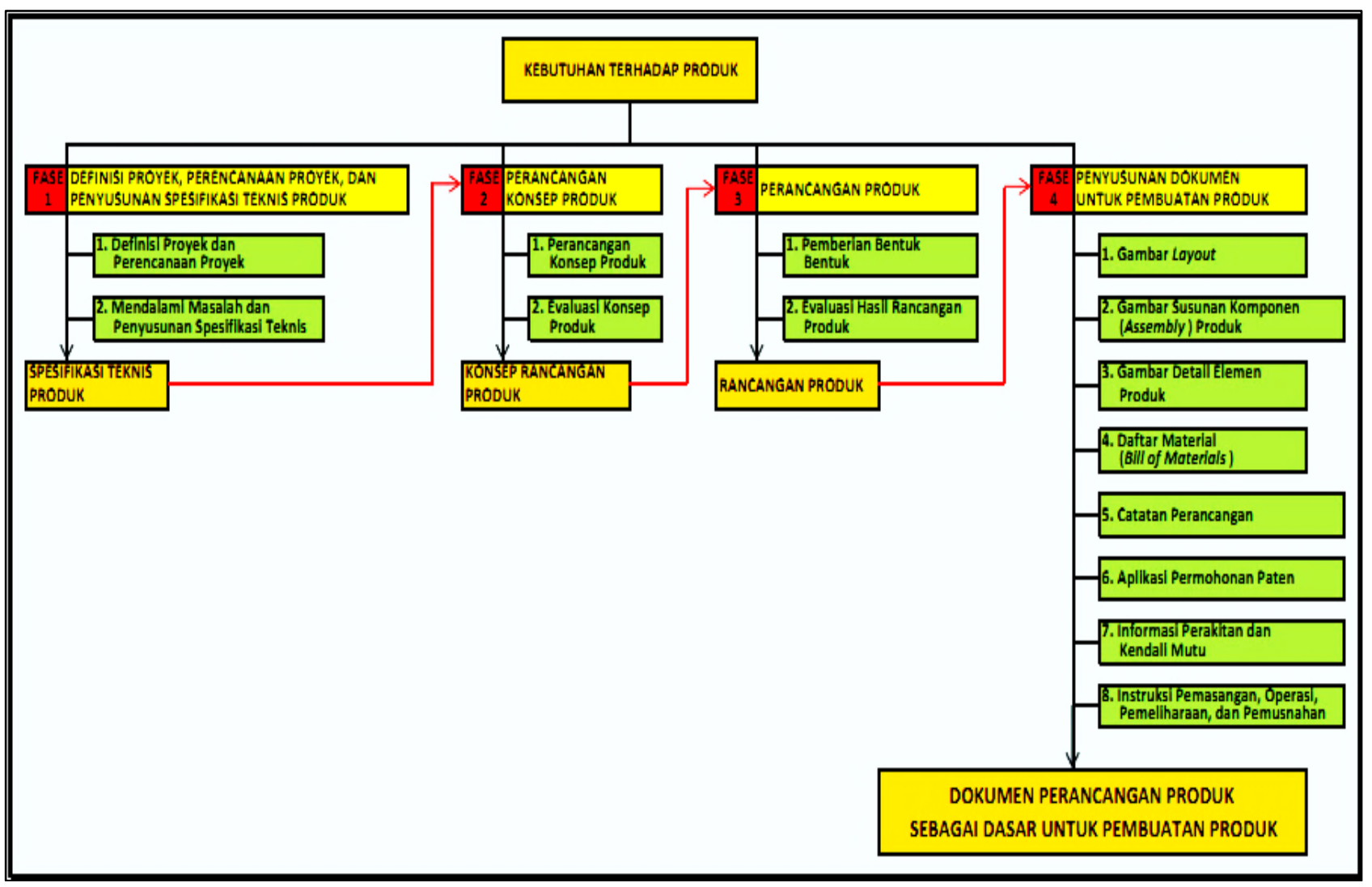

Gambar 4. Diagram alir proses perancangan produk [8]

\section{HASIL DAN PEMBAHASAN}

Makalah ini bertujuan untuk merancang squeeze machine yang dapat membangkitkan deep pressure sebagai perangkat terapi autisme. Hasil rancangan berupa dokumen perancangan produk sebagai dasar untuk pembuatan 
prototipe squeeze machine. Untuk mencapai tujuan tersebut akan diuraikan pada penjelasan hasil dan pembahasan berikut.

\subsection{Hasil}

\subsubsection{Definisi Proyek, Perencanaan Proyek, dan Penyusunan Spesifikasi Teknis Produk}

Ide perancangan squeeze machine dipilih berdasarkan kebutuhan terhadap perangkat terapi autisme, yang sampai saat ini di Indonesia belum ada. Berdasarkan hasil survei dari salah satu pusat terapi autisme "AGCA CENTER", di jalan Ngagel Jaya Tengah III/21 Surabaya, squeeze machine sangat diperlukan selain untuk mengurangi kecemasan dan ketegangan, juga diperlukan untuk menahan dan menghentikan anak autisme pada saat mengalami gangguan perilaku eksesif (berlebihan), seperti hiperaktif dan tantrum (mengamuk). Selama ini untuk mengatasi hal tersebut dilakukan oleh seorang terapis, hal ini kurang efektif dan cukup menyulitkan serta membahayakan. Berikut ini akan dijelaskan mengenai definisi proyek, perencanaan proyek, mendalami masalah, dan menyusun spesifikasi teknis produk.

\subsubsection{Definisi dan perencanaan proyek}

\section{a. Definisi proyek}

Squeeze machine dikenal juga sebagai kotak remas (squeeze box), mesin peluk (hug machine), dan kotak peluk (hug box). Squeeze machine adalah sebuah perangkat terapi autisme sebagai pembangkit deep pressure yang dapat memberikan efek ketenangan terhadap orang yang mengalami sensitivitas tinggi (hypersensitive) terhadap sentuhan dan suara atau keduanya, seperti halnya pada autisme. Selain itu, squeeze machine juga bisa digunakan untuk menahan dan menghentikan anak autisme pada saat mengalami gangguan eksesif, agar berhenti dari mengamuk dan terhindar dari kemungkinan melukai diri sendiri atau orang lain. Rancangan squeeze machine yang dikembangkan terdiri dari tempat tidur yang bisa diatur sudut kemiringannya. Posisi anak autisme tidur telentang dengan mendapat deep pressure dari tiga pasang lengan penekan yang dikontrol sistem pneumatik.

b. Perencanaan proyek

Yang dimaksud dengan proyek disini adalah seluruh kegiatan perancangan. Semuanya harus direncanakan agar berlangsung dengan baik. Yaitu waktu, pekerjaan, biaya dan sumber daya lain, serta mutu produk sesuai dengan yang diinginkan. Penyusunan rencana proyek dilakukan melalui lima langkah, yaitu:

Langkah 1: mengidentifikasi pekerjaan-pekerjaan

Langkah 2: menyusun sasaran setiap pekerjaan (objectives)

Langkah 3: membuat perkiraan tenaga kerja dan waktu yang diperlukan

Langkah 4: menyusun urutan pekerjaan

Langkah 5: membuat perkiraan biaya.

\subsubsection{Mendalami masalah dan menyusun spesifikasi teknis produk}

\section{a. Mendalami masalah}

Squeeze machine terdiri dari sebuah tempat tidur yang bisa diatur sudut kemiringannya. Deep pressure diberikan pada tiga bagian tubuh, yaitu: (1) pada bagian tangan dan badan, (2) pada bagian pinggul dan paha, dan (3) pada kaki bagian bawah. Tekanan kompresor dibatasi antara $30-40$ psi dengan dilengkapi kontrol pneumatik. Pengukuran tingkat stress dilakukan pada jari tengah tangan kiri dalam dua tahap, yaitu sebelum dan sesudah terapi dengan menggunakan alat ukur stress analyzer "uBioClip v70" yang dihubungkan pada komputer.

b. Menyusun spesifikasi teknis produk

Ada beberapa cara untuk menyusun spesifikasi teknis produk, pada umumnya menggunakan metode Quality Function Deployment (QFD). Disamping untuk menyusun spesifikasi teknis produk, metode QFD berguna dalam menghasilkan informasi-informasi penting untuk dapat mengerti secara mendalam tentang masalah produk [8].

\subsubsection{Perancangan Konsep Produk}

Berikut ini ditunjukkan gambar susunan (assembly) konsep rancangan produk, gambar detail elemen produk, dan gambar layout. Dapat dilihat seperti pada Gambar 5, 6 dan 7.

\subsubsection{Konsep rancangan produk}

Model rancangan squeeze machine berawal dari konsep squeeze machine dengan kondisi pemakaian posisi tengkurap, dengan mendapat deep pressure dari sepasang dinding papan yang dilapisi busa empuk berbentuk V. Rancangan squeeze machine yang akan dikembangkan posisinya dibalik, yaitu anak autisme dalam posisi tidur telentang dengan mendapat deep pressure dari tiga pasang lengan penekan yang dikontrol sistem pneumatik. Sehingga sebagian besar badan anak tersebut mendapat tekanan secara mendalam dan merata. Konsep rancangan squeeze machine dapat dilihat seperti pada Gambar 5. 


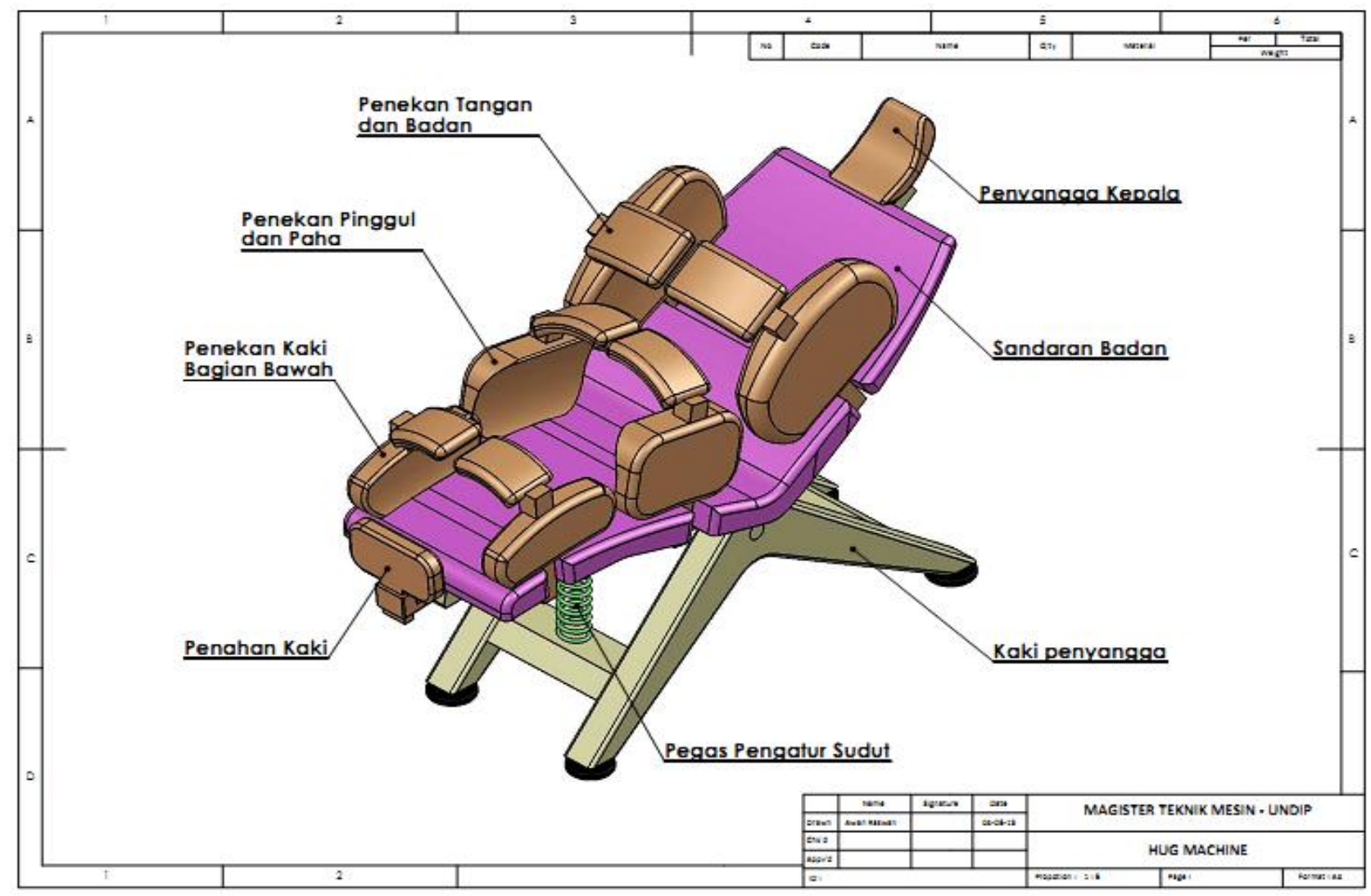

Gambar 5. Gambar susunan (assembly) squeeze machine.

\subsubsection{Gambar detail elemen produk}

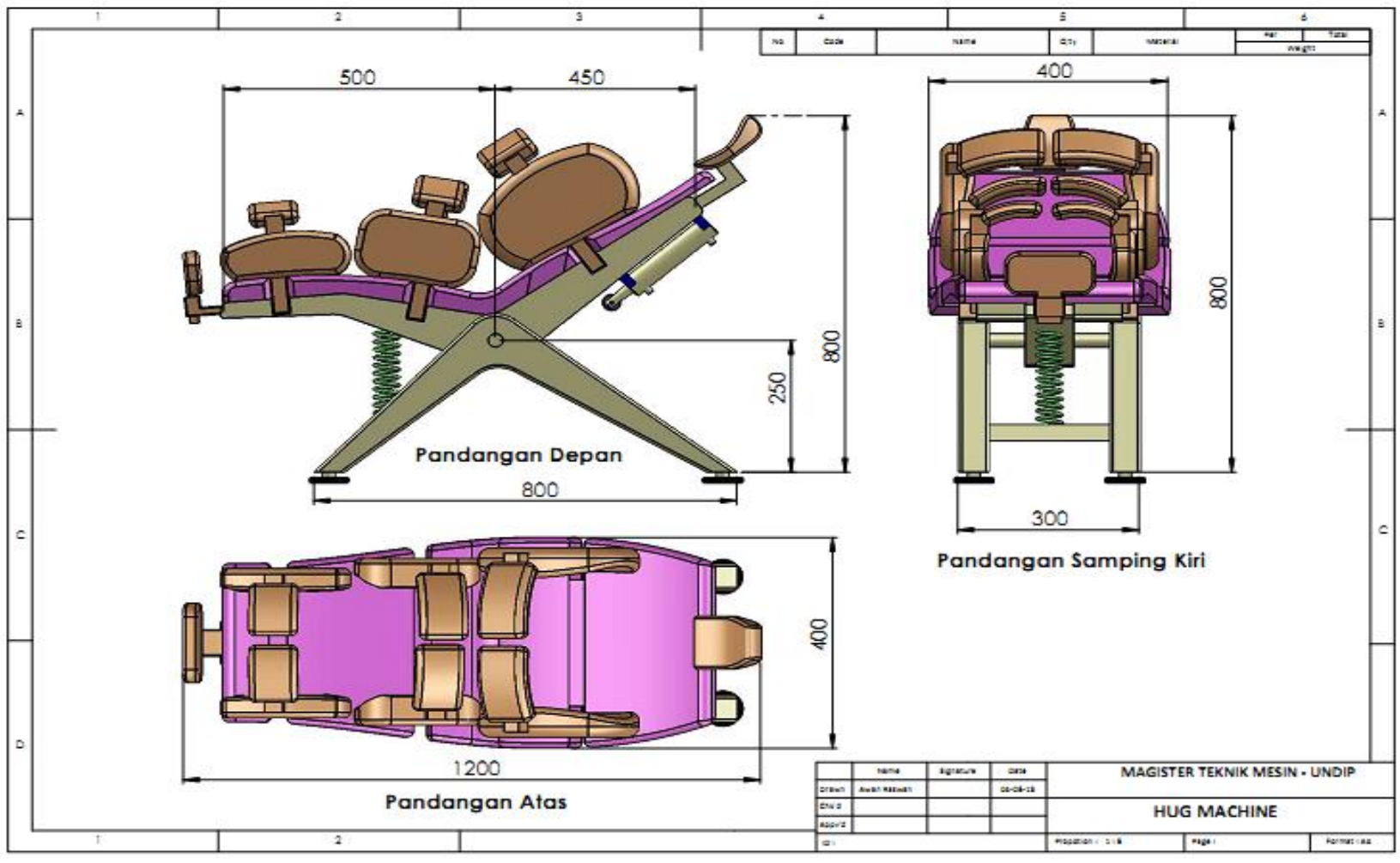

Gambar 6. Gambar detail elemen squeeze machine. 


\subsubsection{Gambar Layout}

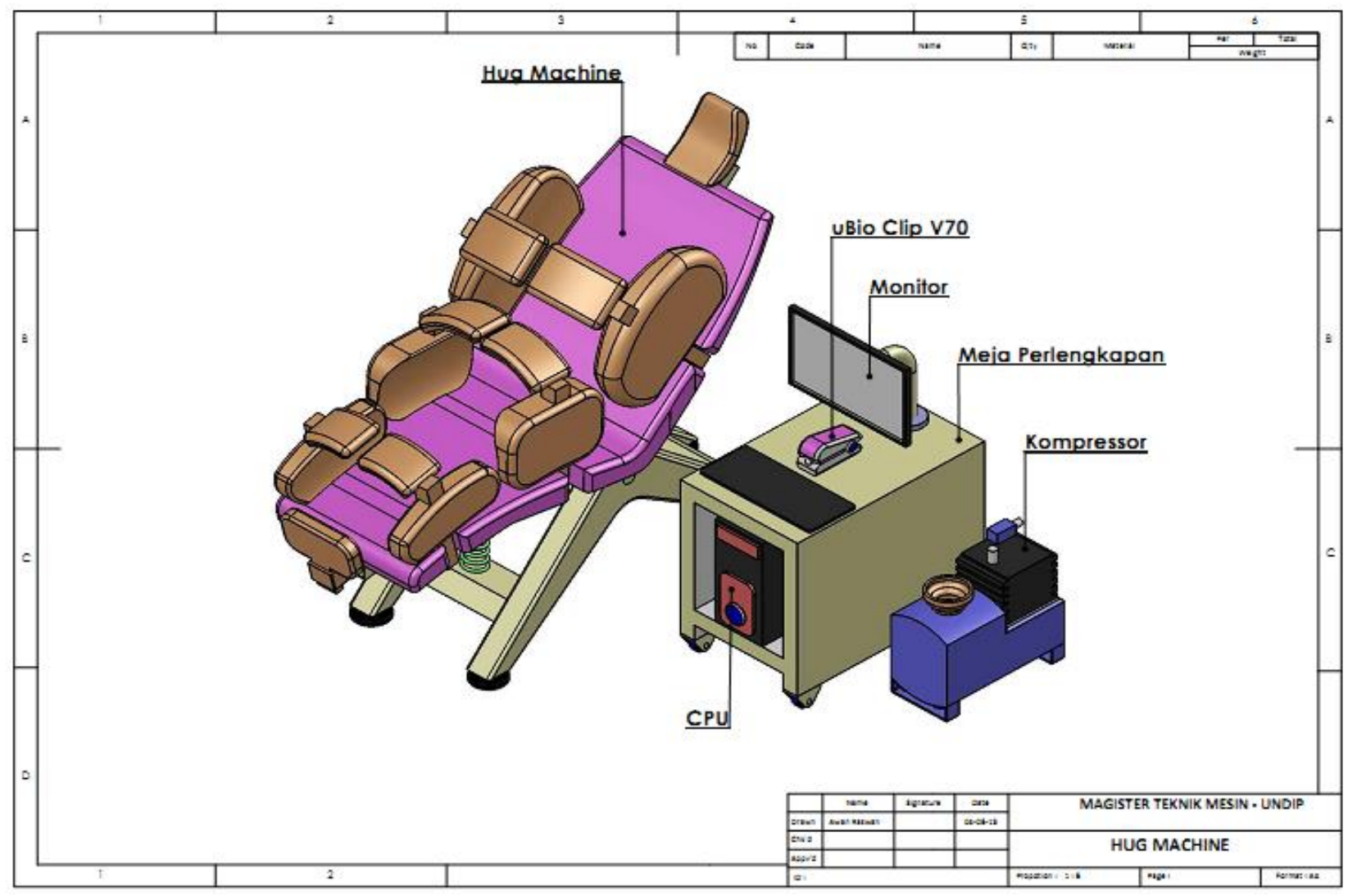

Gambar 7. Gambar layout squeeze machine.

\subsubsection{Spesifikasi teknis produk}

Tabel 1. Spesifikasi teknis squeeze machine

\begin{tabular}{ll}
\hline Anjuran pemakaian (usia anak) & $:$ di bawah $8-9$ tahun \\
Tekanan & $: 30-40 \mathrm{psi}$ \\
Pengaturan sudut & $: 90^{\circ}-180^{\circ}$ \\
Dimensi (panjang x lebar x tinggi) & $: 1200 \times 400 \times 800 \mathrm{~mm}$ \\
Berat & $: 25 \mathrm{~kg}$ \\
\hline
\end{tabular}

Tabel 2. Spesifikasi teknis kompresor

\begin{tabular}{ll}
\hline Anjuran pemakaian & $: 50 \mathrm{psi}$ \\
Voltase & $: 12 \mathrm{~V} / 10 \mathrm{~A}$ \\
Panjang kabel & $: 3000 \mathrm{~mm}$ \\
Dimensi (panjang x lebar x tinggi) & $: 150 \times 120 \times 90 \mathrm{~mm}$ \\
Berat & $: 0,7 \mathrm{~kg}$ \\
\hline
\end{tabular}

\subsection{Pembahasan}

Autisme merupakan gangguan psikologis yang berdampak pada interaksi sosial, sensitif terhadap stimulasi sensorik, sering merasakan kecemasan dan ketegangan. Metode terapi deep pressure merupakan pemberian tekanan dalam besaran dan waktu tertentu secara mendalam pada sebagian besar tubuh bagian luar secara merata dengan menggunakan squeeze machine.

Pada squeeze machine ciptaan Temple Grandin, posisi penggunaannya adalah telungkup dan pemberian deep pressure dari sepasang dinding papan berbentuk V yang dilapisi busa dan ditarik oleh sistem pneumatik. Sebagai ukuran tingkat keberhasilan penurunan stress hanya berdasarkan quesioner atau wawancara dengan pengguna alat tersebut. Tingkatan relaksasi berupa jawaban sesuai dengan yang dirasakan pengguna. Ada beberapa tingkatan yang dirasakan pengguna, yaitu mulai dari skala 1 (hampir tertidur) sampai skala 10 (sangat bersemangat).

Hasil rancangan squeeze machine merupakan perubahan posisi penggunaan dan pemberian deep pressure dari yang telah ada. Pada squeeze machine hasil rancangan dengan penggunaan posisi anak autisme dalam posisi tidur telentang dengan mendapat deep pressure pada tiga bagian tubuh. Penempatan deep pressure, yaitu: (1) pada bagian 
tangan dan badan, (2) pada pinggul dan paha, dan (3) pada kaki bagian bawah. Dengan deep pressure yang diberlakukan untuk anak usia di bawah 8-9 tahun, tekanan diatur pada $30-40$ psi, dan dalam waktu 15 - 45 menit.

Pengukuran indeks stress dilakukan pada jari tangan dengan dua kali pengukuran, yaitu sebelum dan sesudah terapi. Alat ukur yang dugunakan adalah stress analyzer uBioClip v70 yang dihubungkan ke komputer dengan skala pembacaan pada monitor antara 0 - 100. Interpretasi dari indeks stress dinyatakan dalam lima tingkatan, yaitu: (1) di bawah 25: hampir tidak ada stress, (2) 25 - 35: stress ringan/temporer, (3) 35 - 45: stress ringan yang terakumulasi, dan toleransi terhadap stress cenderung melemah, (4) 45 - 60: stress primer, dan (5) di atas 60: stress kronis, disarankan segera berkonsultasi dengan pihak kesehatan profesional.

\section{KESIMPULAN}

Squeeze machine dikenal juga sebagai kotak remas (squeeze box), mesin peluk (hug machine), dan kotak peluk (hug box). Perancangan squeeze machine adalah sebuah proses yang berawal dari ditemukannya kebutuhan terhadap alat ini sampai diselesaikannya gambar-gambar dan dokumen hasil rancangan yang dipakai sebagai dasar untuk pembuatan prototipe. Ada beberapa fase perancangan yang harus dilalui dalam proses perancangan squeeze machine ini, yaitu: (1) fase definisi proyek, perencanaan proyek dan penyusunan spesifikasi teknis produk, (2) fase perancangan konsep produk, (3) fase perancangan pemberian bentuk (embodiment) produk, dan (4) fase penyusunan dokumen untuk pembuatan produk. Dalam fase penyusunan dokumen untuk pembuatan produk diperoleh beberapa dokumen, yaitu: (1) gambar konsep rancangan, (2) gambar layout, (3) gambar susunan komponen (assembly), (4) gambar detail elemen produk, dan (5) daftar material (bill of materials). Sehingga pada akhir proses perancangan, diperoleh dokumen lengkap sebagai dasar untuk pembuatan prototipe squeeze machine.

Dengan hasil rancangan squeeze machine yang berbeda, baik dari segi posisi penggunaan, pemberian deep pressure dan cara pengukuran indek stress, alat ini memiliki kelebihan pada kenyamanan dan tingkat akurasi hasil pengukuran indeks stress yang dilakukan secara kuantitatif dengan menggunakan stress analyzer uBioClip v70. Penggunaan squeeze machine secara terstruktur diharapkan dapat menghilangkan kecemasan dan ketegangan secara permanen. Sehingga menimbulkan anak autisme memiliki rasa percaya diri dan bisa beradaptasi dengan lingkungan hidupnya secara normal serta bisa masuk sekolah seperti layaknya anak seusianya. Pada akhirnya, diharapkan akan lebih banyak lagi anak penyandang autisme yang dapat disembuhkan secara relatif lebih cepat.

\section{REFERENSI}

[1] CDC, (2012), Centers for Desease Control and Prevention, Autism Spectrum Disorder (ASDs)-NCBDDD, http://www.cdc.gov/ncbddd/autism/index.html, Diakses: 4/8/2013, jam 9:19 PM.

[2] Delphie B., (2012), Pembelajaran Anak Tunagrahita, Suatu Pengantar dalam Pendidikan Inklusi, Cetakan kedua, PT. Refika Aditama, Bandung.

[3] Edelson S.M., Kerr D.C., Grandin T., (1999). "Behavioral and Physiologycal Effects of Deep Pressure on Children with Autism: A pilot study evaluating the efficacy of Grandin's Hug Machine”, American Journal of Occupational Therapy, vol. 53, 145-152.

[4] Grandin T., (1992), Calming Effects of Deep Touch Pressure in Patients with Autistic Disorder, College Students, and Animals, Journal of Child and Adolescent Psychopharmacology, Spring, 1992, 2 (1): 63-72. Doi:10.1089/cap.1992.2.63, Volume: 2 Issue 1: June 11, 2009, Mary Ann Liebert, Inc., Publishers.

[5] http://www.psychologymania.com/2012/06/macam-macam-gangguan-autis.html, Diakses: 10/15/2012, jam 13:10 PM.

[6] http://www.therafin.com/images/2011sm.jpg, Diakses: 10/15/2012, jam 14:05 PM.

[7] Handoyo Y., (2003), Autisma: Petunjuk Praktis dan Pedoman Materi untuk Mengajar Anak Normal,Autis dan Perilaku Lain, Cetakan kedua, PT. Bhuana Ilmu Populer, Jakarta.

[8] Harsokoesoemo D.H., (2004), Pengantar Perancangan Teknik (Perancangan Produk), Edisi ke 2, Penerbit ITB, Bandung.

[9] Sutadi R., Bawazir A.L., Tanjung N., Adeline R., (2003), Penatalaksanaan Holistik Autisme, Pusat Informasi dan Penerbitan Bagian Ilmu Penyakit Dalam, Fakultas Kedokteran Universitas Indonesia, Jakarta.

[10] Stephen M.E., (2009), “Temple Grandin's Hug Machine” (htt://www.autism-help.org/point-grandin-hugmachine.html). Salem, Oregon: Center for Study of Autism. (htt://autism-help.org/point-grandin-hugmachine.htm). Retrived 2011-11-09. 